\title{
Atomic-Scale Structure of Biogenic Materials by Total X-ray Diffraction: A Study of Bacterial and Fungal $\mathrm{MnO}_{x}$
}

\author{
V. Petkov, ${ }^{\dagger, *}$ Y. Ren, ${ }^{\neq}$I. Saratovsky, ${ }^{\S}$ P. Pastén, ${ }^{\perp}$ S. J. Gurr, ${ }^{\natural}$ M. A. Hayward, ${ }^{\S}$ K. R. Poeppelmeier, ${ }^{\#}$ and
} J.-F. Gaillard ${ }^{\nabla}$

${ }^{\dagger}$ Department of Physics, 203 Dow Science, Central Michigan University, Mt. Pleasant, Michigan 48859, ${ }^{\ddagger}$ Advanced Photon Source, Argonne National Laboratory, Argonne, Illinois 60439, §Inorganic Chemistry Laboratory, University of Oxford, Oxford, U.K. OX1 30R, ${ }^{\perp}$ Pontificia Universidad Católica de Chile, Santiago, Código Postal 690441, Chile, "Department of Plant Sciences, Oxford University, Oxford, U.K. OX1 3RB, "Department of Chemistry, Northwestern University, Evanston, Illinois 60202, and

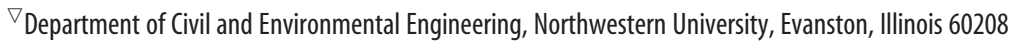

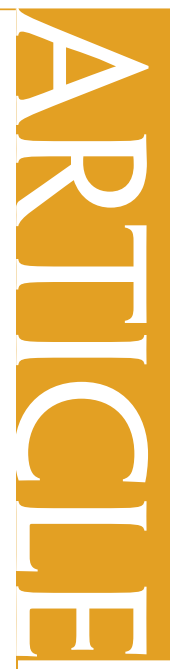

C urrently, technology is looking for smaller scale, ordered materials with well-defined properties.

Nanophase materials are, therefore, being manufactured in increasing numbers. ${ }^{1-3}$ Nature is also a prolific producer of nanophase materials. A typical example of this is the microorganism assisted, or biogenic, oxidation of water-soluble metal ions into insoluble oxides. ${ }^{4}$ Indeed this process has been taking place for millions of years leaving its signature all around: in the sediments on the ocean floor and in the soil on land. Nature's evident success is inspiring and scientists are trying to employ its tools for applications including manufacturing of magnetic nanoparticles ${ }^{5}$ and capturing of contaminant metal ions. ${ }^{6-8}$ Thus understanding the way living microorganisms produce materials, in particular nanophase metal oxides, is becoming important not only for the advance of today's technology but also for remediating some of its unwanted consequences such as metal pollution.

One of the most important prerequisites to understanding a physicochemical process, such as the formation of a nanophase material, is the knowledge of the atomic-scale structure of its product. Recently, good progress has been made in determining the structure of synthetic (i.e., man-made) nanophase materials by employing total X-ray diffraction (XRD) involving a combination of high-energy XRD and atomic pair distribution function (PDF) analysis. ${ }^{9-11}$ This nontraditional approach has also been applied to nanophase materials of geological interest, such as ores. ${ }^{12}$

The approach can also be applied to mate-

www.acsnano.org
ABSTRACT Biogenic materials are produced by microorganisms and are typically found in a nanophase state. As such, they are difficult to characterize structurally. In this report, we demonstrate how high-energy X-ray diffraction and atomic pair distribution function analysis can be used to determine the atomic-scale structures of $\mathrm{MnO}_{x}$ produced by bacteria and fungi. These structures are well-defined, periodic, and species-specific, built of $\mathrm{Mn}-\mathrm{O}_{6}$ octahedra forming birnessite-type layers and todorokite-type tunnels, respectively. The inherent structural diversity of biogenic material may offer opportunities for practical applications.

KEYWORDS: biogenic materials · structure determination $\cdot$ X-ray diffraction - manganese oxides

rials freshly produced by living microorganisms. As an example we consider $\mathrm{MnO}_{x}$ produced by bacteria and fungi. These biogenic materials show a length of structural coherence of about $2-3 \mathrm{~nm}$ only and, in this sense, are in a nanophase state. Nevertheless, their atomic-scale structure is periodic and can be described in simple crystallographic terms. Surprisingly the crystal structures of fungal and bacterial $\mathrm{MnO}_{x}$ turn out to be substantially different indicating that biogenic materials are inherently structurally diverse.

Manganese oxides are ubiquitous in nature ${ }^{13}$ and have been used by mankind for many thousands of years - first as pigments and today as catalysts and battery materials. This has generated a long-lasting interest in their genesis. Several studies on $\mathrm{MnO}_{x}$ produced by microorganisms have been carried out but no complete structural determination has yet been performed. The studies have only suggested that bacterial $\mathrm{MnO}_{x}$ is likely to possess a layered-type structure of the type found in the mineral birnessite. ${ }^{14,15}$ Even less is known about fungal $\mathrm{MnO}_{x}{ }^{16,17}$

\section{*Address correspondence to petkov@phy.cmich.edu.}

Received for review October 3, 2008 and accepted December 30, 2008

Published online January 13, 2009. 10.1021/nn800653a CCC: \$40.75

๑) 2009 American Chemical Society 


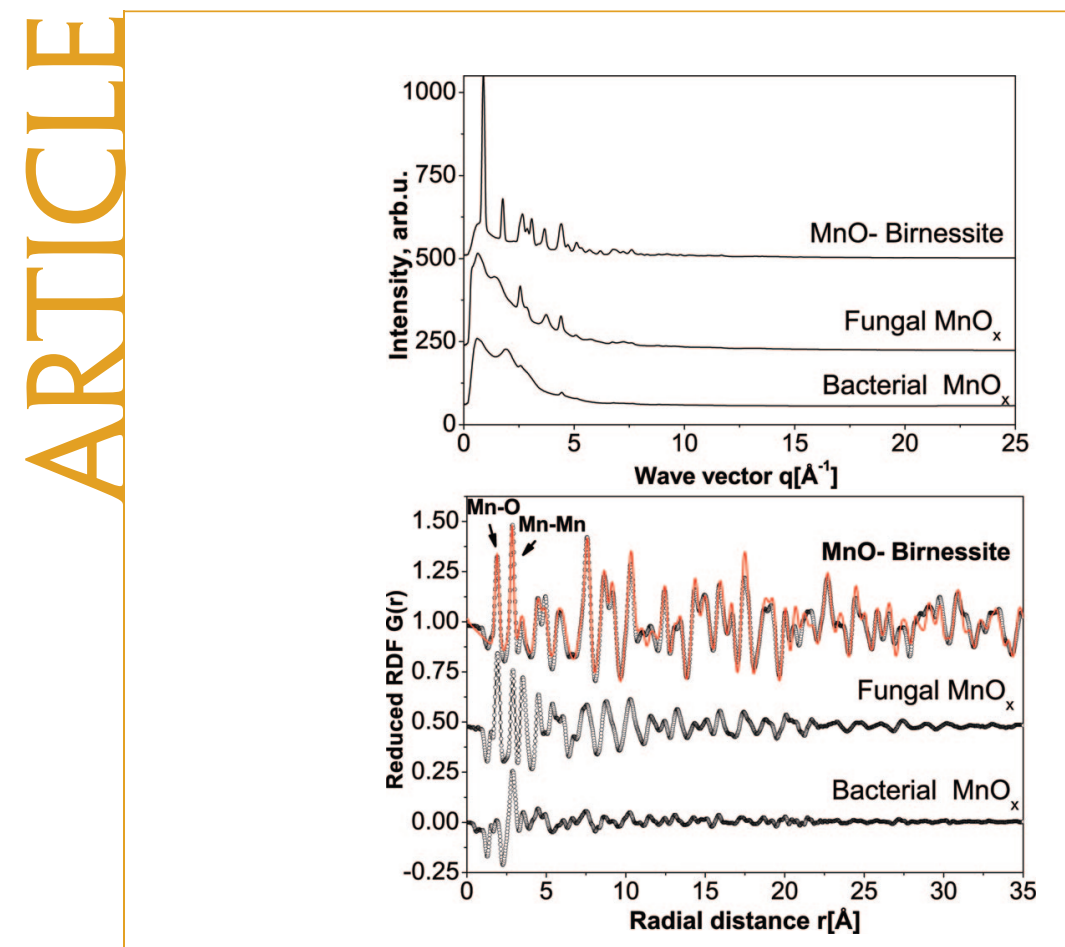

Figure 1. Experimental XRD patterns (upper part) and the corresponding atomic PDFs for crystalline, fungal, and bacterial $\mathrm{MnO}_{x}$. PDF peaks reflecting first neighbor $\mathrm{Mn}-\mathrm{O}$ and $\mathrm{Mn}-\mathrm{Mn}$ correlations are marked with arrows. A model PDF (line in red) based on the structure of hexagonal birnessite is shown as well.

Traditionally the three-dimensional (3D) structure of materials is determined by measuring and analyzing the positions and intensities of the Bragg peaks in their XRD patterns. ${ }^{18}$ Traditional (i.e. Bragg) XRD studies of biogenic materials are possible ${ }^{19}$ but are difficult and are often imprecise. The reason is that biogenic materials are usually highly dispersed and/or of very low crystallinity, often contain water and, as such, show diffraction patterns with a very few, if any, Bragg peaks and a pronounced diffuse component (see Figure 1). Spectroscopy techniques like XANES/EXAFS are also widely used for structural characterization of materials. For biogenic materials, spectroscopy techniques may deliver important information about the valence state of metal ions and their immediate coordination, but are not capable of elucidating the atomic ordering beyond $5-6 \AA$ (e.g., see Figure 1 in Kim et al. $\left.{ }^{20}\right)$. Total XRD is well suited to study materials structured at the nanoscale, as demonstrated recently. ${ }^{9-11,21}$

\section{RESULTS AND DISCUSSION}

Biogenic $\mathrm{MnO}_{x}$ studied here were produced by L. discophora SP- 6 bacteria ${ }^{15}$ and fungi from the Acremonium strictum family. ${ }^{22}$ High-energy XRD patterns for bacterial, fungal, and crystalline $\mathrm{MnO}_{2}$ (birnessite) standard are shown in Figure 1 (the upper part). Sharp Bragg peaks are present in the XRD pattern for synthetic birnessite, as can be expected for a material of good crystallinity. The XRD patterns for both bacterial and fungal $\mathrm{MnO}_{x}$, however, show only a few broad Bragg-like peaks. Such dif-
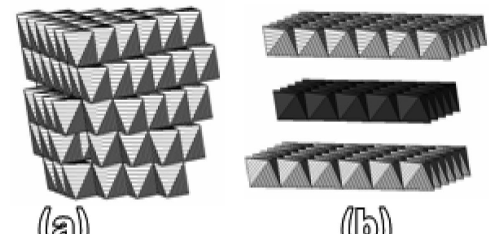

(छ)

([b)
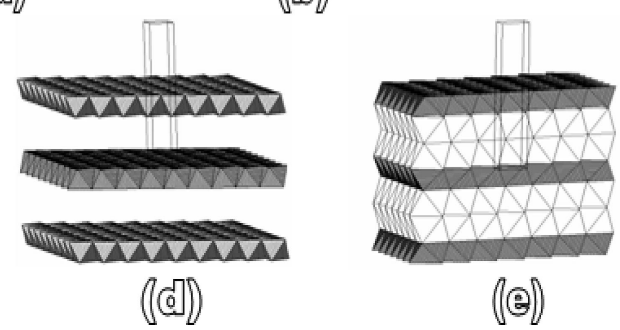

(ङ)

Figure 2. Fragments from the structures of manganosite (a), lithiophorite (b), chalcophanite (c), birnessite (d), and birnessite-like "slabs" of $\mathrm{Mn}-\mathrm{O}_{6}$ octahedra separated by regions scarcely populated with $\mathrm{Mn}$ ions and water (lightly shaded) (e). The unit cells in birnessite and bacterial $\mathrm{MnO}_{x}$ are outlined with thin solid lines.

fuse diffraction patterns are very difficult to analyze by traditional approaches. When considered in real space, in terms of the corresponding atomic PDFs however, they lend themselves to structure search and refinement. ${ }^{21}$ The experimental PDFs $G(r)=4 \pi r\left[\rho(r)-\rho_{0}\right]$, where $\rho(r)$ and $\rho_{o}$ are the local and average atomic number density, respectively, extracted from the XRD patterns are also shown in Figure 1 (the bottom part). As can be seen in the figure the $G(r)$ for birnessite exhibits a series of welldefined peaks to high real-space distances reflecting the presence of a long-range, periodic, atomic ordering. The experimental data can be approximated well in terms of a structure model based on a periodic, hexagonal type lattice (space group, $P \sigma_{3} / m m c$ ) with parameters $a=2.84(1)$ $\AA$ and $c=14.02(1) \AA$, and $M n$ at $(0,0,0)$ and oxygen at $2 / 3$, $1 / 3,0.07$ positions inside the unit cell. The structure features layers of edge sharing $\mathrm{Mn}-\mathrm{O}_{6}$ octahedra, as shown in Figure 2. The excellent level of agreement between the present and previous literature data ${ }^{23}$ for the crystal structure of birnessite demonstrate the fact that atomic PDFs very accurately reflect the $3 \mathrm{D}$ atomic ordering in materials.

As can be seen in Figure 1 the PDFs for both biogenic manganese oxides too show several well-defined peaks but they decay to zero faster (i.e., already at 2-3 $\mathrm{nm}$ ) than those in the PDF for synthetic birnessite, reflecting the limited length of structural coherence in the former materials. The first peak in the PDFs for biogenic $\mathrm{MnO}_{x}$ is positioned at approximately $1.9 \AA$ and the second at approximately $2.85 \AA$. The first two peaks in the PDF for polycrystalline birnessite are positioned at the same distances. Here they reflect the first neighbor $\mathrm{Mn}-\mathrm{O}$ and $\mathrm{Mn}-\mathrm{Mn}$ atomic pairs from edge sharing $\mathrm{Mn}-\mathrm{O}_{6}$ octahedra, respectively. The similarity between the low-r parts of the experimental PDFs in Figure 1 indicates that biogenic $\mathrm{MnO}_{x}$ studied here, like synthetic birnessite, are built up from intercon- 
nected $\mathrm{Mn}-\mathrm{O}_{6}$ octahedra. This conclusion would have been difficult to arrive at if the XRD patterns and not their Fourier transforms, the atomic PDFs, had been considered alone. The higher-r parts (i.e., above 5-6 $\AA$ ) of the experimental PDFs in Figure 1, however, are dissimilar and demonstrate that the longer-range atomic ordering, that is, the way the $\mathrm{Mn}-\mathrm{O}_{6}$ octahedral units connect together and fill up the space, is distinctly different in the three different manganese oxides studied. Such a conclusion is difficult to arrive at on the basis of spectroscopy (e.g., EXAFS) data alone.

To reveal the 3D structure of biogenic $\mathrm{MnO}_{x}$ we tested several structural models as follows: In line with the suggestions of previous studies ${ }^{14,15}$ the PDF for bacterial $\mathrm{MnO}_{x}$ was approached with models featuring layers of $\mathrm{Mn}-\mathrm{O}_{6}$ octahedra. As such we considered the structures of lithiophorite, chalcophanite, and hexagonal and triclinic birnessite (see Figure 2) that occur in $\mathrm{MnO}_{x}$ minerals. As shown in Figure 2 lithiophorite may be viewed as a stack of alternating layers of octahedra, perfect and defect (dark shaded in Figure 2), with the latter layers having 33\% of their octahedral sites vacant. Chalcophanite also features layers of edge-sharing $\mathrm{Mn}-\mathrm{O}_{6}$ octahedra. Here one in seven of the octahedral sites in each of the Mn layers is vacant and the "capping units" (lightly shaded in Figure 2) are positioned exactly above and below the vacancies. Birnessite is a stack of layers of edge-sharing $\mathrm{Mn}-\mathrm{O}_{6}$ octahedra where approximately one in six of the cation sites are vacant. The "missing" Mn cations are positioned between the layers, just above or below the vacant sites. As can be seen in Figure 3 none of those models adequately reproduce the experimental data. The agreement improved when (i) water was introduced between the layers and (ii) the number of vacant metal sites in the layers was increased. Such a model featuring birnessite-type layers where about $30 \%$ of the metal sites are vacant and the "missing" Mn cations have migrated into the interlayer space was indeed able to reproduce the experimental PDF data in good detail, as can be seen in Figure 3. This model structure of bacterial $\mathrm{MnO}_{x}$ may be described well in terms of a triclinic lattice (space group $P 1$ ) with parameters $a=2.832(5)$ $\AA, b=2.866(5) \AA, c=12.6(5) \AA$ and $\alpha=89.3(2), \beta=$ $90.5(5)$, and $\gamma=125.6(5)^{\circ}$. The coordinates of the individual atomic species inside the unit cell are given in the Supporting Information. The refined chemical formula of the material is $\left\{\mathrm{Mn}_{0.3}\right\} .\left[\mathrm{Mn}_{0.7} \square_{0.3}\right] \mathrm{O}_{2} \cdot\left(\mathrm{H}_{2} \mathrm{O}\right)_{5.5}$. Here $\square$ represents the vacant metal positions in the layers of $\mathrm{Mn}-\mathrm{O}_{6}$ octahedra, that is equal to the number of interlayer manganese, $\{\mathrm{Mn}\}$, ions. The relatively high concentration of interlayer $\{\mathrm{Mn}\}$, and associated layer vacancies, is consistent with an average $\mathrm{Mn}$ oxidation state lower than +4 in bacterial $\mathrm{MnO}_{x}$, as found by XANES. ${ }^{15}$

The interlayer $\{\mathrm{Mn}\}$ atoms sit on both sides of the layers and share oxygen atoms from both the $[\mathrm{Mn}-\mathrm{O}]$ layers and the water molecules positioned in between

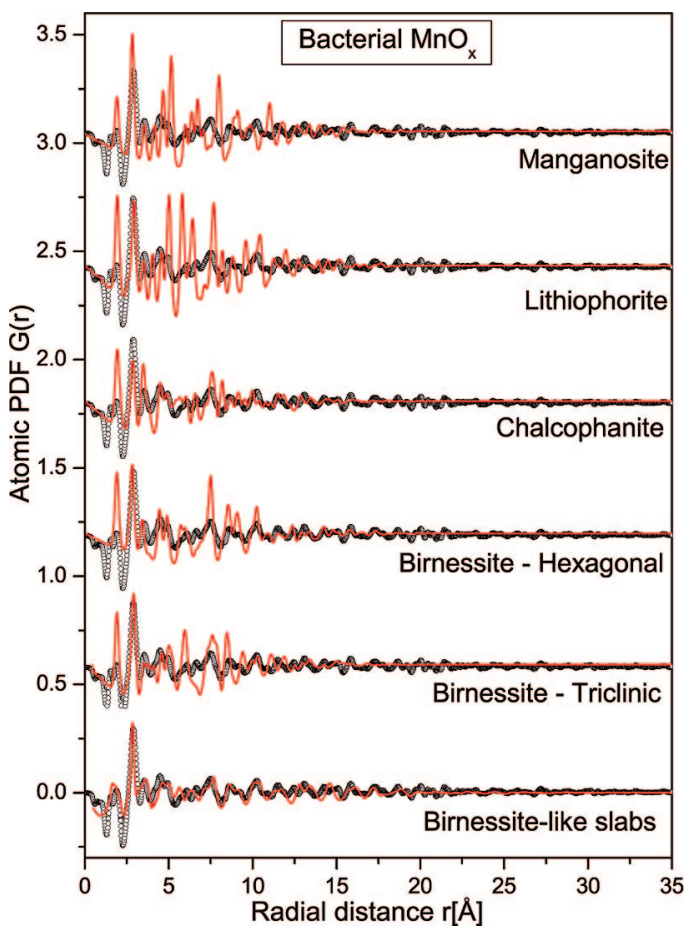

Figure 3. Experimental (symbols) and model (lines in red) atomic PDFs for bacterial MnO. The models are based on the structures of the $\mathrm{MnO}_{x}$ minerals listed in the plot. The low-r part of the data is given in the Supporting Information on an enlarged scale.

these layers. Thus the oxygen coordination of all Mn atoms in bacterial $\mathrm{MnO}_{x}$ appears to be octahedral and the whole material may be viewed as a highly defective "network" of both edge and corner-sharing $\mathrm{Mn}-\mathrm{O}$ octahedra as shown in Figure 2e. The network resembles vaguely that of manganosite (Figure 2a) but in contrast to this material, it exhibits a very nonuniform distribution of $\mathrm{Mn}$ atoms that tend to "cluster" into birnessite-type "slabs" (70\% of all Mn atoms) that are spaced by regions less populated with metal ions (lightly shaded octahedra in Figure 2e). It is in these interlayer regions where water resides. Indeed, according to our study, there are about 5.5 water molecules per $\mathrm{Mn}$ atom in bacterial $\mathrm{MnO}_{x}$. This relatively high water content is consistent with the fact that this biogenic material was formed in an aqueous medium. ${ }^{15}$

As can be seen in Figures 1 and 4, the experimental PDF for fungal $\mathrm{MnO}_{x}$ has a very strong third peak at about $3.45 \AA$. This is the typical separation between $\mathrm{Mn}$ atoms from octahedra that are connected through their vertices. Neither the PDF for birnessite nor that for bacterial $\mathrm{MnO}_{x}$ shows such a strong peak. This observation indicates that the ratio of edge to corner sharing octahedra in fungal $\mathrm{MnO}_{x}$ is different from that seen in layered manganese oxides. This prompted us to look for other types of model structures. As such we considered tunnel-type structures that too are often found in $\mathrm{MnO}_{x}$ minerals. Fragments of the structure models we tested are shown in Figure 5. They included a pyrolusite-type model featuring a dense $3 \mathrm{D}$ framework of edge and corner sharing $\mathrm{Mn}-\mathrm{O}_{6}$ octa- 


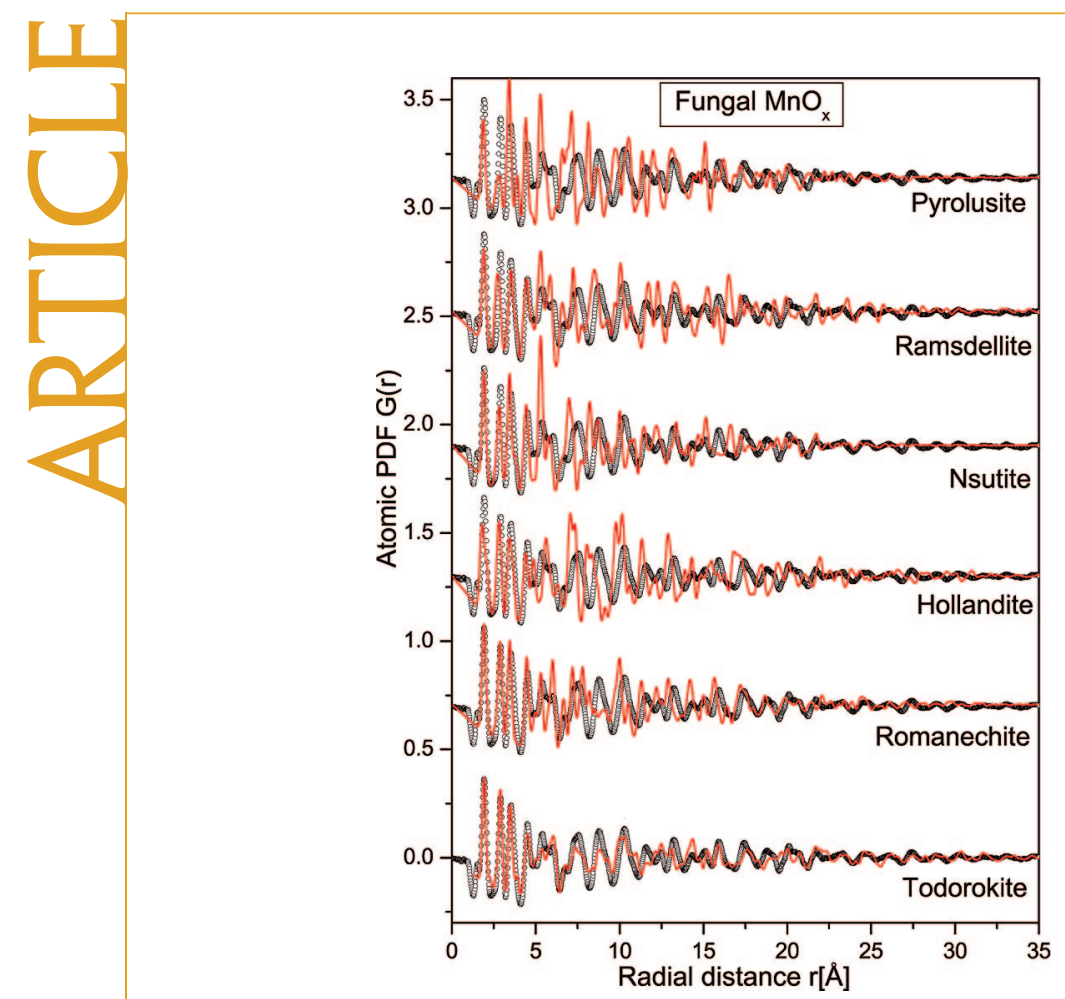

Figure 4. Experimental (symbols) and model (lines in red) atomic PDFs for fungal $\mathrm{MnO}_{x}$. The models are based on the structures of manganese oxide minerals listed in the plot. The low-r part of the data is given in the Supporting Information on an enlarged scale.

hedra, a ramsdellite-type model featuring a framework of $\mathrm{Mn}-\mathrm{O}_{6}$ units having tunnels that are $1 \times 2$ octahedra on a side, an nsutite-type model featuring a framework of $\mathrm{Mn}-\mathrm{O}_{6}$ units having tunnels that are $1 \times 3$ and $3 \times 3$ octahedra on a side, a hollandite-type model featuring a framework of $\mathrm{Mn}-\mathrm{O}_{6}$ units having tunnels with square cross sections measuring $2 \times 2$ octahedra on a side, a romanechite-type model featuring a framework of $\mathrm{Mn}-\mathrm{O}_{6}$ units having tunnels that are $2 \times 3$ octahedra on a side, and a todorokite-type model featuring a framework of $\mathrm{Mn}-\mathrm{O}_{6}$ units having tunnels that are $3 \times 3$ octa-

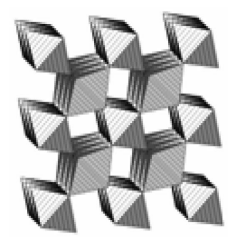

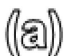

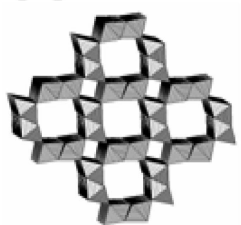

((C)

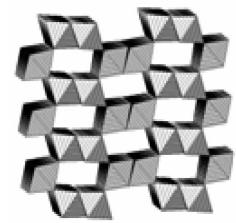

(b))

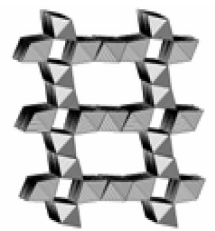

(ब)

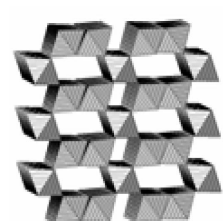

(ब)

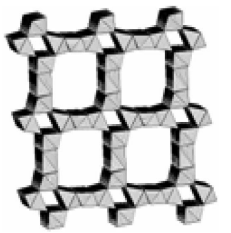

(अ(3)
Figure 5. Fragments from the crystal structures of pyrolusite (a), ramsdellite (b), nsutite (c), hollandite (d), romanechite (e), and todorokite (f). The structures feature open frameworks of $\mathrm{Mn}-\mathrm{O}_{6}$ octahedra. hedra on a side. As can be seen in Figure 4 the last model performed best. Thus, according our study, the 3D structure of fungal $\mathrm{MnO}_{x}$ may be described well in terms of a monoclinic lattice (space group $P 12 / M 1$ ) with parameters $a=9.20(1) \AA, b=2.88(1) \AA, c=9.92(1) \AA$ and $\alpha=90.0$, $\beta=93.52(5)$ and $\gamma=90.0^{\circ}$. The refined chemical formula of the material is $[\mathrm{Mn}] \mathrm{O}_{2} .\left(\mathrm{H}_{2} \mathrm{O}\right)_{0.5}$ indicating an average $\mathrm{Mn}$ oxidation state of +4 . The water content in fungal $\mathrm{MnO}_{x}$, is lower than that found in bacterial $\mathrm{MnO}_{x}$ and is consistent with the fact that the fungal $\mathrm{MnO}_{x}$ formed in a drier medium. ${ }^{22}$ The coordinates of the individual atoms inside the monoclinic unit cell of fungal $\mathrm{MnO}_{x}$ are given in the Supporting Information.

In summary, our study shows that microorganisms produce materials that are nanophase but with welldefined and periodic atomic-scale structures, and that the resulting structure is species-specific. ${ }^{24}$ In particular, microorganisms such as L. discophora SP-6 bacteria that thrive in aquatic environments and oxidize metal ions relatively quickly (i.e., in minutes to hours) are seen to produce layered-type manganese oxides containing a large number of structural defects, and water. In contrast microorganisms such as Acremonium strictum fungi that prefer a less moist environment and oxidize metal ions relatively slowly (i.e., over several days to weeks) are seen to produce tunnel-type manganese oxides that are almost defect-free. Obviously the structure of many materials of biogenic origin, such as deposits, sediments, and ores takes shape at very early stages of their formation, that is, during the oxidation of water-soluble metal ions into nanophase oxides. Given the great diversity of microorganisms that have lived on Earth, it is not difficult to understand why $\mathrm{MnO}_{x}$ of biogenic origin occurs in more than 30 different structure types. ${ }^{13}$

The structural diversity of biogenic materials is not just of academic interest. This seemingly inherent property of biogenic materials may be useful in technological applications. For example, nanophase metal oxides of a particular structure type, and hence particular properties (magnetic, absorptive, catalytic, etc.), may be harvested in a laboratory by choosing an appropriate microorganism and environment, as already demonstrated by Prozorov et al..$^{5}$ In a given environment (e.g., industrial, mining, etc.) a particular type of microorganism may be looked for and chosen over others so that trace metal ions are captured and retained in a material with a more rigid (e.g., dense network) structure. The success of the efforts along these lines will depend on the ability to determine the atomic-scale structure of biogenic materials not only in detail but in terms (e.g., see the Supporting Information) allowing convenient computation and prediction of their properties. Indeed any systematic studies on water soluble metal ions, including verification and refinement of Pourbaix-type diagrams, ${ }^{25}$ would benefit from the ex- 
perimental approach demonstrated here. Total XRD can tackle such nontrivial tasks with success.

\section{METHODS}

Materials Preparation. Bacterial $\mathrm{MnO}_{x}$ studied here was produced by growing a liquid culture of $L$. discophora SP- 6 to a stationary phase at room temperature. The resulting $\mathrm{MnO}_{x}$ was of a fibrillar morphology and with dimensions of the order of $10 \mathrm{~nm}$ wide and $10 \mathrm{~nm}$ long. ${ }^{15}$ Fungal $\mathrm{MnO}_{x}$ studied here was produced by a fungus of the Acremonium strictum family, in particular KR21-2 strain. ${ }^{16,17}$ Since KR21-2 repeatedly failed to produce $\mathrm{MnO}_{x}$ in liquid media a solid agar medium was used. The oxide was grown at room temperature and appeared as particles of an oblong plate morphology, several hundred nanometers to one micrometer in size. ${ }^{22}$

X-ray Diffraction Studies. High-energy XRD experiments were carried out at the beamline 11IDC at the Advanced Photon Source, Argonne National Laboratory using X-rays of energy $115.232 \mathrm{keV}(\lambda=0.1076 \AA)$ and a large area (mar345) detector. Fresh samples of biogenic $\mathrm{MnO}_{x}$ were sealed in glass capillaries and data taken at room temperature. Synthetic crystalline $\mathrm{MnO}_{2}$ powder (birnessite) was also measured and used as a standard.

Atomic PDFs Data Analysis and Structure Modeling. The processing of the raw XRD data and derivation of atomic PDFs was done with the help of the program RAD. ${ }^{26}$ The test and refinement of structure models was done with the help of the program PDFFIT. $^{27}$

Acknowledgment. K.R.P. and J.F.G. acknowledge support from the EMSI program of NSF and DOE at the NU institute for Environmental Catalysis. V.P. acknowledges support from CMU through Grant REF 60628. Work at APS was supported by DOE under Contract No. DE-AC02-06CH11357. I.S., M.H., and S.G. acknowledge the support of the EPSRC Adventurous Chemistry program.

Supporting Information Available: Structure data for fungal and bacterial $\mathrm{MnO}_{x}$. This material is available free of charge via the Internet at http://pubs.acs.org.

\section{REFERENCES AND NOTES}

1. lijima, S.; Ichihashi, T. Single-shell Carbon Nanotubes of 1nm Diameter. Nature 1993, 363, 603-605.

2. Alivisatos, P. Nanocrystals: Building Blocks for Modern Materials Design. Endeavour 1997, 21, 56-60.

3. Parak, W. J.; Pellegrino, T. Plank, Ch. Labelling of Cells with Quantum Dots. Nanotechnology 2005, 16, R9-R25.

4. Banfield, J. F.; Welch, S. A.; Zhang, H.; Ebert, T. T.; Penn, R. L. Aggregation-Based Crystal Growth and Microstructure Development in Natural Iron Oxyhydroxide Biomineralization Products. Science 2000, 289, 751-754.

5. Prozorov, T.; Palo, P.; Wang, L.; Nilsen-Hamilton, M.; Jones, D.; Orr, D.; Mallapragada, S. K.; Narisamhan, B.; Canfield, P. C.; Prozorov, R. Cobal Ferrite Nanocrystals: OutPerforming Magnetotactic Bacteria. ACS Nano 2007, 1, 228-233.

6. Ambashta, R. D.; Wattal, P. K.; Singh, S.; Bahadur, D. Nanoaggregates of Hexacyanoferrate-Loaded Magnetite for Removal of Cesium from Radioactive Wastes. J. Magn. Magn. Mater. 2003, 267, 335-340.

7. Webb, S. M.; Bargar, J. R.; Tebo, B. M. Determination of Uranyl Incorporation into Biogenic Manganese Oxides Using X-Ray Absorption Spectroscopy and Scattering. Phys. Scr. 2005, T115, 949-952.

8. Waychunas, G. A.; Kim, Ch. S.; Banfield, J. F. Nanoparticulate Iron Oxide Minerals in Soils and Sediments: Unique Properties and Contaminant Scavenging Mechanisms. J. Nanopart. Res. 2005, 7, 409-433.

9. Petkov, V.; Zavalij, P. Y.; Lutta, S.; Whittingham, M. S.; Parvanov, V.; Shastri, S. Structure beyond Bragg: Study of $\mathrm{V}_{2} \mathrm{O}_{5}$ Nanotubes. Phys. Rev. B 2004, 69, 085410-6.
10. Petkov, V.; Bedford, N.; Knecht, M. R.; Weir, M. G.; Crooks, R. M.; Tang, W.; Henkelman, G.; Frenkel, A. Periodicity and Atomic Ordering in Nanosized Particles of Crystals. J. Phys. Chem. C 2008, 112, 8907-8911.

11. Petkov, V.; Buscaglia, V.; Buscaglia, M.; Zhao, Zh.; Ren, Y. Structural Coherence and Ferroelectricity Decay in Submicron- and Nano-sized Perovskites. Phys. Rev. B 2008, 78, 054107-7.

12. Michel, F. M.; Ehm, L.; Antao, S. M.; Lee, P. L.; Chupas, P. J.; Liu, G.; Strongin, D. R.; Schoonen, M. A. A.; Phillips, B. L.; Parise, J. B. The Structure of Ferrihydrite, a Nanocrystalline Material. Science 2007, 316, 1726-1729.

13. Post, J. E. Manganese Oxide Minerals: Crystal Structures and Economic and Environmental Significance. Proc. Natl. Acad. Sci. U.S.A. 1999, 96, 3447-3454.

14. Jürgensen, A.; Widmeyer, J. R.; Gordon, R. A.; Bendell-Yong, L. L.; Moore, M. M.; Crozier, E. D. The Structure of the Manganese Oxide on the Sheath of the Bacterium Leptothrix discophora: An XAFS study. Am. Mineral. 2004, 89, 1110-1118.

15. Saratovsky, I.; Wightman, P. G.; Pasten, P. A.; Gailard, J-F.; Poeppelmeier, K. R. Manganese Oxides: Parallels between Abiotic and Biotic Structures. J. Am. Chem. Soc. 2006, 128, 11188-11198

16. Miyata, N.; Tani, Y.; Iwahori, K.; Soma, M. Enzymatic Formation of Manganese Oxides by an Acremonium-Like Hyphomycete Fungus, Strain KR21-2. FEMS Microbiol. Ecol. 2006, 47, 101-109.

17. Miyata, N.; Sugiyama, D.; Tani, Y.; Tsuno, H.; Seyama, H.; Sakata, M.; Iwahori, K. Production of Biogenic Manganese Oxides by Repeated-Batch Cultures of Laboratory Microcosms. J. Biosci. Bioeng. 2007, 103, 432-439.

18. Giacovazzo, C., Ed. Fundamentals of X-ray Crystallography; Oxford University Press: New York, 1998.

19. Villalobos, M.; Lanson, B.; Manceau, A.; Toner, B.; Sposito, G. Structural Model for the Biogenic Mn Oxide Produced by Pseudomonas putida. Am. Mineral. 2006, 91, 489-502.

20. Kim, H-S.; Pasten, P. A.; Gaillard, J-F.; Stair, P. C. Nanocrystalline Todorokite Oxide produced by Bacterial Catalysis. J. Am. Chem. Soc. 2003, 125, 14284-1285.

21. Egami, T.; Billinge, S. J. L. In Underneath the Bragg Peaks; Pergamon Press: Amsterdam, The Netherlands, 2003.

22. Saratovsky, I.; Gurr, S. J.; Hayward, M. A. The structure of manganese oxide formed by the fungus Acremonium sp Strain KR21-2. Submitted for publication.

23. Gaillot, A-C.; Flot, D.; Drits, V. A.; Manceau, A.; Burghammer, M.; Lanson, B. Structure of synthetic K-rich birnessite obtained by high-temperature decomposition of $\mathrm{KMnO}_{4}$. Chem. Mater. 2003, 15, 4666-4678.

24. Indeed todorokite-type tunnel and birnessite-type layered structures found in biogenic $\mathrm{MnO}_{x}$ are closely related to each other. The latter may be transformed into the former via a hydrothermal treatment and cation exchange, as discussed by: Luo, J.; Zhang, Q.; Huang, A.; Giraldo, O.; Suib, S. L. Double-aging Method for Preparation of Stabilized Na-Buserite and Transformations to Todorokites Incorporated with various Metals. Inorg. Chem. 1999, 38, 6106-6113.

25. Lin, H. Y.; Sun, Y. P.; Weng, B. J.; Yang, C. T.; Suen, N. T.; Liao, K. H.; Huang, Y. C.; Ho, J. Y.; Chong, N. S.; Tang, H. Y. Factors Determining the Structure of Electrochemically Prepared $\gamma-\mathrm{MnO}_{2}$ and $\alpha-\mathrm{MnO}_{2}$ phases. Electrochim. Acta 2007, 52, 6548-6553.

26. Petkov, V. RAD, a Program for Analysis of X-ray Diffraction Data from Amorphous Materials for Personal Computers. J. Appl. Crystallogr. 1989, 22, 387-389.

27. Proffen, Th.; Billinge, S. J. L. PDFFIT, a Program for Full Profile Structural Refinement of the Atomic Pair Distribution Function. J. Appl. Crystallogr. 1999, 32, 572-575. 